The main biochemical study of the retina has always been study of the light-sensitive pigments themselves. This brief review can discuss only one class, namely, those which are contained in the rod cells of vertebrate retinas and are thought to be the basis of vision in dim lights where colours are not appreciated. These pigments, the rhodopsins and porphyropsins, are lipoproteins with carotenoid chromophores, the carotenoid being retinene $A_{1}$, the aldehyde of vitamin $A_{1}$, or retinene $A_{2}$, the aldehyde of vitamin $A_{2}$. It is interesting that the first connexion between vitamin $A$ and visual pigments came from study of human and experimental night blindness and that later biochemical work showed the vitamin to be a part of the pigment molecule. Rhodopsin can be isolated from the rod cells by extraction with digitonin with which it forms a soluble complex. It is a red pigment which fades to a yellow when exposed to light. This red pigment was first seen in the frog retina by Boll in 1876, who noticed that it faded in light but was re-formed if the live animal or separated eye was left in the dark.

The breakdown of rhodopsin by light and its reformation in darkness has been studied by examination of changes in the absorption spectrum. Mammalian rhodopsin has an absorption maximum at $500 \mathrm{~m} \mu$, which is also the wave-length of light to which the mammalian eye is most sensitive. Change in absorption at $500 \mathrm{~m} \mu$ measures change in rhodopsin. The primary action of light can be studied by determining change at very low temperatures, $-70^{\circ} \mathrm{C}$., where thermal reactions are stopped. Such experiments show that light does not, strictly speaking, bleach rhodopsin but only changes the point of maximal absorption very slightly to the blue. Subsequent reactions which occur in light or in the dark cause more profound changes with release of retinene. Recent work of Wald and Hubbard has suggested that the retinene present in rhodopsin is a particular 11-cis stereoisomer and that the action of light is to change this isomer to the all-trans form while leaving it still attached to the protein. Vitamin $A$ and retinene in other parts of the body are the all-trans isomers, but the pigment epithelium in mammalian eyes and the eyes of some marine crustaceans contain 11-cis retinene. The mechanism of formation of this isomer in the eye is not clear. Wald found it less effective than the all-trans isomer in promoting regeneration of rhodopsin in the retina of the vitamin A-deficient rat.

Examination of the density of rhodopsin in the living eye has shown that visual sensitivity is not related directly to rhodopsin concentration. Bleaching half a per cent of the total rhodopsin reduces sensitivity three-thousand-fold. Probably neural factors as well as pigment concentration are involved.

Apart from the light-sensitive pigments of the visual cells there are other pigments in the eye that modify the light stimulus received. For example, there is a yellow pigment, probably the carotenoid xanthophyll, at the macula, where vision is most acute in the human eye. This absorbs about 60 per cent of all incident blue light. The retinal pigment epithelium or choroid of many fish, amphibians and at least one reptile contains fluorescent pterins, and similar parts of the eyes of other species of fish and some mammals are rich in riboflavin. The most extreme example is the eye of the lemur, Galego crassicaudatus, in which there is a layor of crystals of riboflavin immediately behind the visual cells. This mirror will both reflect light and, through its fluorescence, will transform short-wave blue light to light of longer wave-length $(520 \mathrm{~m} \mu)$ to which rhodopsin is more sensitive.

Many animals have elaborated mirrors behind their retinas or on their irises. Carnivores have a layer of crystals of zinc cysteine; and in the silver fox the zinc concentration of this part of the eye may reach 16 per cent of the dry weight. This is also the basis of the eye shine of dogs and eats. Fish and amphibians lay down crystals of guanin as a mirror in their eyes as in their scales (fish silver), while lemurs have crystals of riboflavin. The biochemical processes whereby these substances are concentrated to such an extent that they crystallize have yet to be investigated.

The study of both the specialized and the general biochemistry of eye tissues is only just beginning to expand. It is a fascinating study, and should lead to a clearer understanding of normal and abnormal processes in the eye as well as giving information which is interesting in connexion with the metabolism of other tissues.

\title{
OBITUARIES
}

\section{Prof. H. W. B. Skinner, F.R.S.}

Herbert Skinner, Lyon Jones professor of physics in the University of Liverpool, died suddenly in Geneva on January 20, at the age of fifty-nine, leaving a wife and daughter. His death was a great shock to a wide circle of friends and colleagues, for he was well known and liked far beyond his own University.

He was educated at Rugby and Trinity College, Cambridge, and worked under Rutherford at the Cavendish Laboratory until 1927, when he joined Tyndall at Bristol. He was elected to the Royal Society in 1942 in recognition of his work on the soft X-ray spectroscopy of metals.

Early in the War, Skinner worked on radar at the Telecommunications Research Establishment, which was a remarkably successful amalgamation of academic, industrial and Government scientists working in close liaison with the communications industry and the Royal Air Force. Skinner was one of the bright spirits of this enterprise and certainly contributed much to its success. He left in 1943 to join the atomie weapons work under the Department of Scientific and Industrial Research, and went to California as a senior member of the British group working with $\mathrm{E}$. O. Lawrence and his colleagues on the electromagnetic separation of uranium isotopes.

Skinner returned to act as deputy to Sir John Cockeroft, who was still in Canada, in setting up the Atomic Energy Research Establishment at Harwell. He and a few colleagues began the creation of a great research laboratory from an empty R.A.F. station on the edge of the Berkshire Downs. Looking back now, it is remarkable that such impressive progress was made in those early years, when conditions were 
so difficult. Skinner's contribution, first acting in Cockcroft's absence and later as one of his able lieutenants, was a most important one. His particular personal creation was the General Physics Division which, organizationally, could have no logical justification but was a reflexion of his own wide interests and was extremely productive. Under his personal supervision came the synchrocyclotron, cloud chamber and nuclear emulsion work, synchrotrons, linear accelerators and electronics instrumentation, X-ray and neutron diffraction, isotope separation and mass spectrometry, and, later, extra-mural work on plasma physies. All this work prospered and, with the growth of Harwell, some found homes in new divisions.

Four years later, when chief physicist at Harwell, Skinner was appointed to succeed Sir James Chadwick at Liverpool. There he had further opportunity to exploit his talent for construction, because Chadwick, having created a flourishing school of nuclear physics around one of the first cyclotrons in Europe, had undertaken the construction of a new research laboratory centred on a 156-in. synchrocyclotron. This large project was in an early and critical stage, but was brought to a highly successful conclusion with the help of Chadwick's former colleagues and new men brought in by Skinner. Unlike Chadwick, Skinner was not primarily a nuclear physicist, and he appointed J. M. Cassels as professor of experimental physics. Liverpool became the home of a powerful school of high-energy physies, and the research work more than kept pace with the general growth in the universities. The small cyclotron, together with a Cockcroft-Walton generator, enabled the traditional nuclear physics school at Liverpool to grow in size and output to such good effect that one of Skinner's last acts was to undertake the installation of a tandem electrostatic generator for further expansion in this field. This machine is still being manufactured, and it is tragic that Skinner will not see it installed. A new and impressive building, the Chadwick Physies Laboratory, for teaching and research was completed recently under his guidance.

Skinner was active in the work of the European Organization for Nuclear Research (CERN) and was the senior British consultant in the $600-\mathrm{MeV}$. synchrocyclotron project. He was chairman of the CERN Panel of the Department of Scientific and Industrial Research, concerned with British participation in CERN'S work, and served on the Nuclear Physics Sub-Committee. He remained keenly interested in atomic energy, and was a consultant to the Atomic Energy Authority and a member of the Nimrod Project Committee. The National Institute for Research in Nuclear Science has good reason to be grateful for his advice and help on numerous occasions, and he was an active and provocative member of several committees of the Institute. He brought his laboratory into the national Liquid Hydrogen Bubble Chamber project sponsored by several British universities.

Herbert Skinner was devoted to physics and to physicists, and was generous with his time and energies. He hated red tape and sometimes alarmed administrators. Unconventional, persistent in argument and often disconcerting in management, he was also sincere, gentle and kind to an extent not always understood by his critics. $\mathrm{He}$ and his wife Erna were generous in hospitality, and their home was often crowded with guests. The affairs of physicists are duller without him.

\section{T. G. Pickavance}

\section{Prof. Marcel Schein}

ON February 20, at the height of his scientific career, Marcel Schein died in Chicago, Illinois. With him disappeared a most brilliant, able and imaginative scientist whose work is destined to leave an enduring mark in the physies of our century.

Marcel Schein was born in Tresten, Czechoslovakia, on June 9, 1902. After studying in Prague, Vienna, Würtzburg and Zurich, he received a doctorate in physies at the University of Zurich in 1927. His first academic appointment was that of assistant in physics in that University. Between 1929 and 1930 he spent a year in Chicago on a Rockefeller Fellowship. He then returned to Zurich as a docent, a position which he held until 1935, when he was appointed professor of physics at the University of Odessa. In 1938, Mareel Schein wont to settle permanently in the United States, at the invitation of Prof. A. H. Compton. He joined the University of Chicago where he remained until his death, holding various positions until, in 1946, he was appointed professor in the Department of Physics and in the Institute of Nuclear Studies. In 1927, while in Zurich, he married the former Hilde Schoenbeck, who was working as a Ph.D. candidate in the Physics Department. From this marriage he had a son, Edgar, who is now on the faculty of the School of Industrial Management at the Massachusetts Institute of Technology.

In the early years of his scientific career, Marcel Schein made some valuable contributions to the physics of X-rays. He is best known, however, for his work in cosmic rays, which he began after moving to Chicago in 1938. At that time it was known that the primary radiation consisted, at least to a large extent, of positively charged particles. The possibility that these particles might be protons had been suggested; however, there was no direct experimental evidence to support this assumption. Indeed, the prevailing view was still that primary cosmic rays were for the most part positive and negative electrons. During 1938-41, Marcel Schein conducted a series of balloon experiments in which he studied the physical properties of cosmic-ray particles in the highest layers of the atmosphere and was able to show that these particles did not behave in at all the way that high-energy electrons were known to behave. He concluded that electrons did not appear in any appreciable amount among primary cosmic rays, and that the incoming radiation consisted most likely of protons ${ }^{1}$.

These experiments remain one of the milestones of cosmic-ray research. However, they were only the beginning of Marcel Schein's work in this field of science. Soon his interest became focused on the most energetic particles present in the primary cosmic radiation and on the remarkable and unbelievably intricate processes that occur when these particles strike atomic nuclei. Marcel Schein was a pioneer in the study of nuclear interactions at energies far exceeding those provided by man-made machines. At the time of his death, he had just returned from an expedition to the Caribbean where, in an effort to extend further and improve the experimental data on high-energy interactions, he had flown the largest stack of nuclear emulsions ever used in any experiment. This stack, which is now being processed, will undoubtedly contain invaluable data the analysis and interpretation of which will keep many physicists busy for a number of years. 